\title{
Sound Pressure Level Analysis of Commercials and Regular Programs
}

\author{
P. MALECKI* AND J. WiCIAK \\ Faculty of Mechanical Engineering and Robotics, Department of Mechanics and Vibroacoustics \\ AGH University of Science and Technology, al. Mickiewicza 30, 30-059 Kraków, Poland
}

Popularity of television and multitude of commercials during the TV broadcast lead to the analysis of its sound levels. Costs of commercials' time cause producers to make commercials much louder than a regular TV program. The article shows results of commercials and regular program sound level (RMS and FFT) analysis and the difference in sound levels of commercials compared to a regular program. The analysis also shows the difference between public and private TV. The authors of the article suggest a solution to this problem and its effects.

PACS numbers: 43.50.Sr, 43.50.Rq, 43.50.Yw

\section{Sound level of commercials}

Competition of the mass media market and corporations economy policy have made commercials almost inseparable part of the television and the radio. The commercials producers want to make the strongest impression on potential clients in the shortest, very expensive broadcast time. The result of this situation is that the perceptible sound pressure level of commercial brakes is much higher than the level of regular programs. This is very uncomfortable situation for the audience which forces them to use a remote to change the level all the time. This disproportion is a source of noise that disturbs spare time and affects the state of mind. Furthermore there is no established measure procedures or any standards so nobody has ever performed any of such a research in Poland [1].

This article shows the results of sound pressure level comparison between commercials and the regular programs in general and with divisions into theme categories. The comparison is made for public and private TV too. The calculated difference is plotted as a spectrum so there is a possibility of referring results to human isophonic curves. However, the main goal of researches is to find a relative difference between SPL for different kinds of TV programs especially considering commercials.

\section{Measurements methodology}

The measurements are made on the recorded samples of TV program. The representative samples of respective TV programs and two different channels with speech and

\footnotetext{
* corresponding author; e-mail: pawel.malecki@agh.edu.pl
}

music were recorded on $\mathrm{PC}$ computer hard drive and then analyzed. Figure 1 shows the scheme of the recording track.
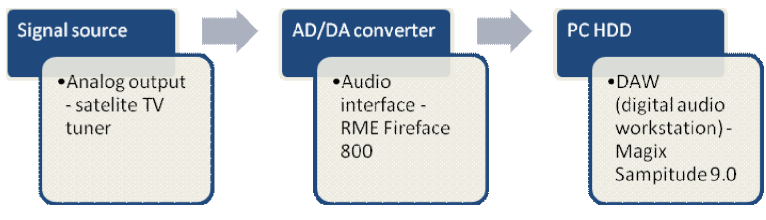

Fig. 1. The recording track.

The whole recorded material is normalized (the highest modulus value of single sample is found and is assigned to value 1 in 16 bit data resolution format and all other samples are proportionally multiplied too) and divided into particular categories e.g. film, commercials etc. It was recorded more than $17 \mathrm{~h}$ of sound samples ( $8 \mathrm{~GB}$ of $44100 \mathrm{~Hz}$ sample rate and 16 bit resolution *.wav format). It is noticed that commercials are almost $30 \%$ of broadcast on both public and private TV. Recordings have been made during two working days at the same time of a day from about 2 p.m. to 10 p.m. The first day on public TV and second day on private TV. All the recorded sound material is analyzed in Matlab 6.5 environment [2] using the authors' script to calculate RMS levels and the spectrum of signal and difference of signals $[3,4]$. Calculations are made using following algorithm:

- Load *.wav file to Matlab (maximum file length is 15 minutes because of RAM memory in limitation of $\mathrm{x} 32$ OS).

- Filter signal to $\langle 16 \mathrm{~Hz}: 16 \mathrm{kHz}\rangle$ frequency range to eliminate infra and ultrasound noise from signal using 30 order Butterworth band-pass filter. 
- RMS level analysis of signal using time constant FAST $(0.125 \mathrm{~s})$. There was no averaging in time domain. All particular values were saved to *. mat file to allow statistic processing of whole data set. Figure 2 shows exemplary set of results.

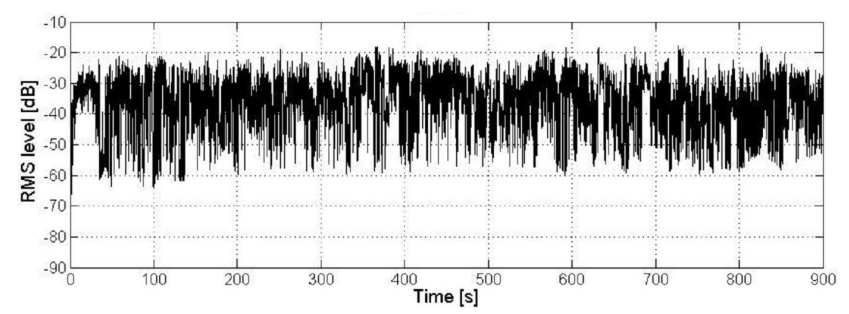

Fig. 2. Exemplary RMS plot.

- Octave filter of signal in main octave bands and RMS level calculating of every frequency band using the same settings as in a previous point.

- FFT (Fast Fourier Transform) using time constant SLOW (1 s) with resolution $N=2^{12}$ [samples]. Every single $1 \mathrm{~s}$ period was multiplied by Hamming window. All single spectrums were saved to *. mat file.

- Load all results and statistic, graphic process of data.

\section{Measured levels analysys}

The analysis are made considering two major classifications of recorded material. The division on theme categories and comparison of particular channels shows main disproportion and the audience group most exposed to commercials noise.

\subsection{SPL analysis of TV commercials and regular programs with category classification}

Recorded TV broadcast can be divided into several theme categories:

(a) commercials,

(b) film,

(c) entertainment/news,

(d) programs for children.

This division allows for showing audience groups exposed to commercial noise. Table I. shows average RMS levels of signal and particular frequency bands levels too. Regular programs refers to all programs except commercials. Values in [dB FS] refers to Full Scale of signal quantization. As it is said in chapter 2.1, signal is normalized, so the highest peak of recorded signal would have level which could equal $0 \mathrm{~dB}$ FS. On the other hand, average level of white noise using FAST time constant would have level equaling $-6 \mathrm{~dB}$ FS and pink noise would have level being equal to $-13 \mathrm{~dB} F \mathrm{~F}$.

RMS levels of particular program categories and difference between them.

TABLE I

\begin{tabular}{|c|c|c|c|c|c|c|c|c|c|}
\hline$L_{\mathrm{RMS}}[\mathrm{dB}$ FS] - filter & {$[20 \mathrm{~Hz}-16 \mathrm{kHz}]$} & {$[63 \mathrm{~Hz}]$} & {$[125 \mathrm{~Hz}]$} & {$[250 \mathrm{~Hz}]$} & {$[500 \mathrm{~Hz}]$} & {$[1 \mathrm{kHz}]$} & {$[2 \mathrm{kHz}]$} & {$[4 \mathrm{kHz}]$} & {$[8 \mathrm{kHz}]$} \\
\hline Commercials & -20.8 & -38 & -31.5 & -29.5 & -30.8 & -34 & -34.4 & -35.9 & -37.8 \\
\hline Regular programs & -28.3 & -49.9 & -41.7 & -36.9 & -36.6 & -40.3 & -42.5 & -45.5 & -50.6 \\
\hline Difference* $^{*}$ & 7.5 & 11.9 & 10.2 & 7.4 & 5.8 & 6.3 & 8.1 & 9.6 & 12.8 \\
\hline Film & -28.9 & -50.7 & -42 & -37 & -37.4 & -42.1 & -43 & -46 & -51.6 \\
\hline Difference* & 8.1 & 12.7 & 10.5 & 7.5 & 6.6 & 8.1 & 8.6 & 10.1 & 13.8 \\
\hline Entertainment/news & -26.3 & -47.6 & -40.2 & -35.2 & -34.7 & -38.5 & -41 & -44.2 & -47.8 \\
\hline Difference* & 5.5 & 9.6 & 8.7 & 5.7 & 3.9 & 4.5 & 6.6 & 8.3 & 10 \\
\hline For children & -35.4 & -58 & -48.5 & -43.8 & -42.5 & -44.7 & -46.6 & -51.3 & -60.4 \\
\hline Difference* & 14.6 & 20 & 17 & 14.3 & 11.7 & 10.7 & 12.2 & 15.4 & 22.6 \\
\hline
\end{tabular}

The results in the Table I show that the average RMS level of commercials signal is $7.5 \mathrm{~dB}$ higher than level of other programs. The highest disproportion $(14.6 \mathrm{~dB})$ is in programs for children and the smallest one in the entertainment/news category $(5.5 \mathrm{~dB})$. The film category is closest to general difference level but it is probably the consequence of proportion of broadcast time for particular categories. The spectrum of calculated differences is presented in Fig. 3. It is significant that in all cases spectrum shapes are similar and that the biggest differences are in low and high bands.

It is hard to refer results with psychoacoustic human perception of loudness and especially to associate it with physical values of signal difference. There are some models showed in references $[5,6]$ but none of them are exact or confirmed. In general, the biggest difference is in fre- 


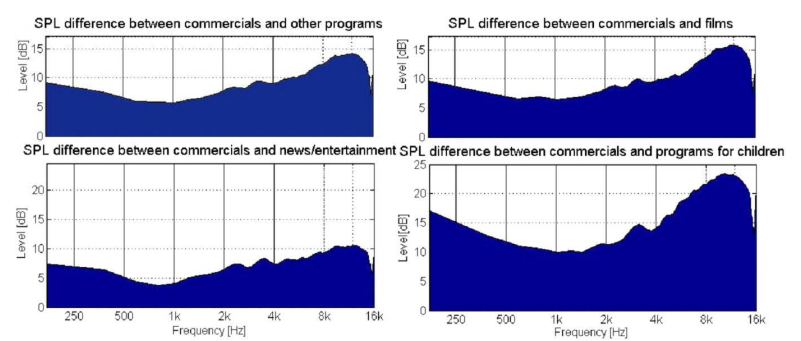

Fig. 3. Spectrums of calculated differences.

RMS levels of particular channels.

\begin{tabular}{|c|c|c|c|c|c|c|c|c|c|}
\hline$L_{\mathrm{RMS}}[\mathrm{dB}$ FS] - filter & {$[20 \mathrm{~Hz}-6 \mathrm{kHz}]$} & {$[63 \mathrm{~Hz}]$} & [125 Hz] & {$[250 \mathrm{~Hz}]$} & [500 Hz] & {$[1 \mathrm{kHz}]$} & {$[2 \mathrm{kHz}]$} & {$[4 \mathrm{kHz}]$} & {$[8 \mathrm{kHz}]$} \\
\hline A-Commercials PUBL & -23.6 & -40.8 & -34.1 & -32.2 & -33.5 & -37.2 & -37.7 & -39 & -40.7 \\
\hline B - Commercials PRIV & -19.8 & -36.9 & -30.5 & -28.6 & -29.7 & -32.8 & -33.1 & -34.8 & -36.8 \\
\hline $\mathrm{C}$ - Regular programs PUBL & -32.1 & -54.1 & -45.8 & -40.5 & -40.1 & -44.2 & -45.6 & -48.8 & -54.6 \\
\hline D - Regular programs PRIV & -24.7 & -44.7 & -37.6 & -33.2 & -33.1 & -37.3 & -40 & -43.3 & -47.5 \\
\hline$A-C^{*}$ & 8.5 & 13.3 & 11.7 & 8.3 & 6.6 & 7 & 7.9 & 9.8 & 13.9 \\
\hline$B-D^{*}$ & 4.9 & 7.8 & 7.1 & 4.6 & 3.4 & 4.5 & 6.9 & 8.5 & 10.7 \\
\hline $\mathbf{B}-\mathbf{A}^{*}$ & 3.8 & 3.9 & 3.6 & 3.6 & 3.8 & 4.4 & 4.6 & 4.2 & 3.9 \\
\hline $\mathbf{D}-\mathbf{C}^{*}$ & 7.4 & 9.4 & 8.2 & 7.3 & 7 & 6.9 & 5.6 & 5.5 & 7.1 \\
\hline
\end{tabular}

The results in the Table II. and in the Fig. 4. show that sound pressure levels of private TV are higher at general. Difference between SPL of commercials is equal to $3.8 \mathrm{~dB}$ and for regular programs is equal to $7.4 \mathrm{~dB}$. Such difference can be the result of few reasons. Firstly, it could be a difference caused by signal normalization of the whole material (not every particular channel). Secondly, it could be result of channels content because the private TV has much more entertainment and popular programs that could be louder than a cultural and education programs on public TV. On the other hand, nowadays it is hard to notice the difference between public and private TV considering its content. The disproportion is bigger on regular programs and has non flat spectrum like on commercials level difference spectrum.

On the other hand the levels difference between commercials and regular programs is bigger for private TV than a public. According to authors reconnaissance and public opinion pools made at other research centers [7], subjective loudness of commercials is more annoying on private TV than on a public one.

This two opposite conclusions induce to perform more insightful psychoacoustic estimation of TV programs loudness perception. It requires more measurements and psychoacoustic subjective listening tests. However this kind of research needs extra funding.

\section{Measured levels statistic analysys}

All the previous results have shown average SPL level. quencies out of speech bands. It means that loudness perception of real signal would be higher than measurements using SPL meter with correction.

\subsection{SPL difference analysis between commercials and regular programs in association with channels}

The measurements were made on two different channels - a private one (PRIV) and public TV channel (PUBL). Table II. shows calculated RMS levels on both channels and the essential differences between them.

\section{TABLE II}


cials probability distributions are even less similar to normal distribution than a probability distribution of regu- lar programs which is clearly represented by almost two times bigger kurtosis [9].

TABLE III

Descriptive statistic estimators.

\begin{tabular}{c|c|c|c|c|c|c}
\hline \hline & 10th percentile [dB] & 1st quartile [dB] & median [dB] & 3rd quartile [dB] & 90th percentile [dB] & kurtosis \\
\hline Regular programs & -43.9 & -35.2 & -26.7 & -20.6 & -17.4 \\
Commercials & -38.7 & -30.0 & -24.0 & -20.3 & 3.27 \\
Difference & 5.2 & 5.2 & 2.7 & 0.3 & -18.1 & -0.7
\end{tabular}

Calculated statistic estimator in Table III shows that biggest difference is between percentiles 10th and 25th (in both cases difference is equal to $5.2 \mathrm{~dB}$ ). Difference between the medians is almost two times smaller and is equal to $2.7 \mathrm{~dB}$. The values of $3 \mathrm{rd}$ quartile and $90 \mathrm{th}$ percentile are very similar as well on commercials as on regular programs. This are very valuable information which explains subjective loudness difference of signals which has the same signal peak limits.

\section{The results estimation}

\subsection{Binding in law restrictions that apply to considering problem}

Nowadays there are no any law restrictions which are referred to SPL of TV programs or commercials $[1,10]$. More than there is no legal basis in media binding statute to apply the considering problem. In spite of many TV audience complains about it the legislator cannot enforce any restrictions about it. In media authorities opinion it is very hard to define and proof any harmful influence of commercial noise to humans [11].

In authors opinion there is some way to estimate effect of calculated disproportions. Because of fact that human ear response is different for different SPL, sound engineers has standardized operating levels in sound productions studios. Table IV shows the standard operating levels for film and television sound work. It also includes an approximate range for music mixing, although this is not a standard level $[12,13]$.

\section{TABLE IV}

Standard operating levels for mixing [12].

\begin{tabular}{c|c|c}
\hline \hline Medium & Signal level [dB FS] & Acoustic level [dB SPL] \\
\hline Film & -20 & 85 \\
Television & -20 & 79 \\
Music & -20 & $79-82$
\end{tabular}

We can conclude from this that at least sound producers, conscious audience and audiophiles are exposed to danger SPL commercial noise because acoustic level of commercials would be in this case around $90 \mathrm{~dB}$ SPL.
For mass audience the difference of $8 \div 9 \mathrm{~dB}$ SPL, which translates to almost 8 times energy increase, would certainly cause at least uncomfortable situation and what is even more important, the most exposed audience are children who have more sensitive hearing so this problem should not be ignored.

\subsection{Suggested solutions}

The authors suggest performing similar measurements for all Polish television channels and on the basis of differences in average SPL, they also suggest obliging the producers/channels to reduce its broadcast levels by measured and calculated values. New regulations about commercials [14] contains methodology of signal measurements but there are no any results of current differences between commercials and other programs so it is hard to predict effectiveness of proposed regulations.

\section{References}

[1] Interpellation No 6978 to Prime Minister of Poland about too high SPL of TV commercial (in Polish). http://orka2.sejm.gov.pl/IZ6.nsf/main/ 18D0F100 . Retrieved 2009-11-23.

[2] A. Everest. Master Handbook of Acoustics. McGraw-Hill, (2008).

[3] A. Zalewski, R. Cegieła, Matlab: numerical calculations and their application (in Polish). Wydawnictwo Nakom, (1996).

[4] T.P. Zieliński, Digital Signal Processing (in Polish). Wydawnictwo Komunikacji i Łączności, Warszawa, (2007).

[5] B.C.J. Moore, An Introduction to the Psychology of hearing. Elsevier Academic Press, (2004).

[6] E. Ozimek, Sound and perception (in Polish). PWN, Warszawa-Poznań, (2002).

[7] K. Makowski, A. Furmann, Sound loudness of television sets (in Polish). Master Thesis, Adam Mickiewicz University in Poznan, (2008).

[8] Z. Engel, The environment protection against noise and vibrations (in Polish). PWN, Warszawa, (1993).

[9] R. Scheaffer, J. McClave, Probability and Statistics for Engineers. PWS-KENT Publishing Company, Boston, (1986). 
[10] The Ministry of Culture and National Heritage answer - under the authority of Prime Minister - to interpellation No 6978 (in Polish). http://orka2.sejm.gov.pl/IZ6.nsf/main/ 3533C17D . Retrieved 2009-11-23.

[11] B.C.J. Moore, B.R. Glasberg, M.A. Stone, J. Audio Eng. Soc., Vol. 51, 12, 1123 (2003).
[12] M. Geoff, B. Mus, M. Mus, Introduction to Sound Recording. Geoff Martin, (2004).

[13] B. Owinski, Calibrating the 5.1 system. Surround Professional, (1988).

[14] The National Broadcasting Council Regulations from 2009-12-15 (in Polish). http://www.krrit.gov.pl/ bip/LinkClick. aspx?fileticket $=0 \mathrm{Hf}$ j frcGUSM \%3d\&tabid=36 . Retrieved 2010-01-15. 